\title{
The HDAC6 inhibitor ACY-1215 enhances the anticancer activity of oxaliplatin in colorectal cancer cells
}

\author{
DONG HOON LEE ${ }^{1,2}$, HYE-RIM WON ${ }^{1}$, HYUN-WOOK RYU ${ }^{1}$, JUNG MIN HAN ${ }^{1,2}$ and SO HEE KWON ${ }^{1}$ \\ ${ }^{1}$ College of Pharmacy, Yonsei Institute of Pharmaceutical Sciences, Yonsei University, Incheon 21983; \\ ${ }^{2}$ Department of Integrated OMICS for Biomedical Science, Yonsei University, Seoul 03722, Republic of Korea
}

Received November 1, 2017; Accepted April 12, 2018

DOI: $10.3892 /$ ijo.2018.4405

\begin{abstract}
ACY-1215, also known as ricolinostat, is a leading histone deacetylase 6 inhibitor, which is currently being tested in clinical trials for hematological malignancies. Previous studies have reported that ACY-1215 is not potent enough as a monotherapy for the treatment of colorectal cancer (CRC), which generally requires combination therapy for successful treatment. Therefore, the present study aimed to determine whether the synergistic interaction detected between ACY-1215 and anticancer agents in hematological cancers could occur in solid tumors. The results of the present study indicated that ACY-1215 exerted a potent synergistic anti-proliferative effect when used in combination with anticancer agents in CRC cells. The combination of ACY-1215 and oxaliplatin was more potent than either drug alone, as indicated by an increase in apoptotic cells and their effects on the apoptotic pathway; ACY-1215 and oxaliplatin cotreatment activated caspase-3 and poly (ADP ribose) polymerase, increased B-cell lymphoma (Bcl)-2 homologous antagonist/killer expression, and decreased Bcl-extra large protein, phosphorylated-extracellular signal-regulated kinase and phosphorylated-protein kinase $B$ expression. In addition, combined treatment of ACY-1215 and anticancer agents induced synergistic upregulation of programmed death-ligand 1. These findings suggested that a therapeutic strategy that combines ACY-1215
\end{abstract}

Correspondence to: Professor So Hee Kwon, College of Pharmacy, Yonsei Institute of Pharmaceutical Sciences, Yonsei University, 85 Songdogwahak-ro, Yeonsu-gu, Incheon 21983, Republic of Korea E-mail: soheekwon@yonsei.ac.kr

Abbreviations: Bcl-xL, B-cell lymphoma-extra large protein; $\mathrm{CI}$, combination index; CRC, colorectal cancer; ERK, extracellular signal-regulated kinase; $\mathrm{F}_{\mathrm{A}}$, fraction affected; 5-FU, 5-fluorouracil; HDAC, histone deacetylase; HDACi, histone deacetylase inhibitor; PARP, poly (ADP ribose) polymerase; PD-L1, programmed deathligand 1; SAHA, suberoylanilide hydroxamic acid; STAT3, signal transducer and activator of transcription 3

Key words: HDAC6, ACY-1215, oxaliplatin, colorectal cancer, combination therapy, apoptosis and oxaliplatin warrants attention for the treatment of solid tumors, including CRC.

\section{Introduction}

Colorectal cancer (CRC) is the third most prevalent type of carcinoma and the second leading cause of cancer-associated mortality in western countries (1). At present, $>1$ million people are newly diagnosed with CRC every year and $~ 50 \%$ of patients with CRC develop metastatic diseases. Although research has been conducted on the pathogenesis of CRC, the molecular mechanisms underlying CRC remain largely unknown (2). Combinations of anticancer agents form the basis for treatment of CRC and have improved the overall survival outcome; however, despite the availability of novel classes of drugs, advanced inoperable CRC remains incurable. Therefore, further research is required to identify novel therapeutic agents and develop more effective combination strategies for CRC treatment.

Histone deacetylase (HDAC)6 is a unique class IIb HDAC with two deacetylase domains and a C-terminal zinc-finger domain $(3,4)$. HDAC6 is mainly localized in the cytosol, where it performs diverse functions through deacetylation of numerous targets, including $\alpha$-tubulin, heat shock protein 90 and cortactin (5). HDAC6 acts as a master regulator of cellular protective responses, including misfolded protein-induced aggresomes, autophagy and stress granules (6-8). Selective inhibition of HDAC6 exerts antitumor effects by inducing differentiation, cell cycle arrest, apoptosis, responsiveness to chemotherapy, and inhibition of migration and angiogenesis (5). Recently, research focusing on the development of a HDAC6-selective inhibitor has increased, since among the HDACs only HDAC6 inhibition does not cause major side effects (9). Therefore, HDAC6 is considered a promising target in drug development for cancer therapy.

Numerous HDAC6-selective inhibitors have been reported and tested as anticancer drugs (10-14). Tubacin and tubastatin A have been reported to be the most effective HDAC6-selective inhibitors $(15,16)$; however, both have non-druggable qualities, including non-drug-like structure, high lipophilicity and complex synthesis, and are therefore used primarily as research tools (17). ACY-1215, also known as ricolinostat, is the only first-in-class clinically relevant HDAC6 inhibitor (13). Ricolinostat is currently being studied in clinical trials (18), 
both as a monotherapy, and in combination with dexamethasone and proteasome inhibitors (bortezomib) (19), or immunomodulatory drugs [lenalidomide (20) and pomalidomide] in multiple myeloma (MM). Ricolinostat has also been evaluated in a clinical trial as a monotherapy in relapsed/ refractory (R/R) lymphoid malignancies (NCT02091063) (21).

Despite these advances, the antitumor effects of ACY-1215 on solid tumors remain to be evaluated, and its clinical efficacy in solid tumors remains elusive. Therefore, the present study aimed to determine whether similar interactions occurred with the HDAC6-selective inhibitor ACY-1215 in solid tumors as in hematological cancers. The present study investigated the preclinical anticancer activity of ACY-1215 in CRC, either alone or in combination with chemotherapeutic agents, including 5-fluorouracil (5-FU), oxaliplatin and irinotecan. The results indicated that ACY-1215 may interact synergistically with oxaliplatin in $\mathrm{CRC}$, resulting in the induction of apoptosis, and inhibition of numerous signaling pathways and antitumor immune responses. In addition, ACY-1215 exhibited slight synergism with irinotecan. Collectively, these findings suggested that targeting HDAC6 activity using ACY-1215 may present a promising therapeutic opportunity that improves the sensitivity of solid tumors to conventional therapy.

\section{Materials and methods}

Cell culture and drug treatment. The human HCT116 and HT29 CRC cell lines were purchased from American Type Culture Collection (Manassas, VA, USA) and were cultured in Dulbecco's modified Eagle's medium (HCT116) and RPMI-1640 medium (HT29) (HyClone; GE Healthcare, Logan, UT, USA) containing $10 \%$ fetal bovine serum (HyClone; GE Healthcare), $100 \mathrm{U} / \mathrm{ml}$ penicillin and $100 \mu \mathrm{g} / \mathrm{ml}$ streptomycin (Gibco; Thermo Fisher Scientific, Inc., Waltham, MA, USA) in a humidified atmosphere containing $5 \% \mathrm{CO}_{2}$ and $95 \%$ air at $37^{\circ} \mathrm{C}$. Each cell line was treated with dimethyl sulfoxide (DMSO), suberoylanilide hydroxamic acid (SAHA; Sigma-Aldrich; Merck KGaA, Darmstadt, Germany) $(5 \mu \mathrm{M})$, ACY-1215 (ricolinostat) (0.01, 0.05, 0.1, 0.2, 0.5, 1, 2, 5, 10 and $20 \mu \mathrm{M}), 5-\mathrm{FU}(1,5$ and $10 \mu \mathrm{M})$, oxaliplatin $(2,10$ and $20 \mu \mathrm{M})$ or irinotecan $(1,2,5$ and $10 \mu \mathrm{M})$ (all from Selleck Chemicals Houston, TX, USA).

Cell growth and viability assay. Cell growth and viability were assessed by measuring the dye absorbance of the water-soluble tetrazolium salt, WST-8 [Cell Counting kit (CCK)-8 kit, Dojindo Molecular Technologies, Inc., Kumamoto, Japan], according to the manufacturer's protocol. Cells were seeded in triplicate at a density of $0.5-1 \times 10^{4}$ cells in $200 \mu 1$ medium in 96-well plates. The drugs were added to the cells at the indicated concentrations $24 \mathrm{~h}$ after seeding at $37^{\circ} \mathrm{C}$ for $72 \mathrm{~h}$. Cells in each well were pulsed with $20 \mu \mathrm{l}$ WST- 8 for the final $3 \mathrm{~h}$ of a 72-h incubation and absorbance was then measured at $450 \mathrm{~nm}$ using a multimode microplate reader (Tecan Group, Ltd., Mannedorf, Switzerland). For cell growth analysis, cell counts were indirectly estimated from absorbance measurements, relative to a standard curve generated using solutions of known cell counts $\left(0.5 \times 10^{4}, 1 \times 10^{4}, 2 \times 10^{4}, 3 \times 10^{4}, 4 \times 10^{4}\right.$, $5 \times 10^{4}, 6 \times 10^{4}, 7 \times 10^{4}$ and $8 \times 10^{4}$ cells/well). Absorbance was normalized to that of the negative control (no DMSO vehicle) at each time interval. To analyze cell viability, the absorbance percentage was calculated relative to negative control cultures. Results are presented from three independent experiments performed in triplicate.

Inhibitory assays. The present study determined the drug concentrations that inhibited $50 \%$ of cell growth $\left(\mathrm{GI}_{50}\right)$ and $50 \%$ of cell viability $\left(\mathrm{IC}_{50}\right)$ using a CCK-8 assay. All cell lines were treated for $72 \mathrm{~h}$ on day 2 , unless otherwise stated. $\mathrm{GI}_{50}$ and $\mathrm{IC}_{50}$ were determined using Prism version 6.0 software (GraphPad Software, Inc., La Jolla, CA, USA).

Acid extraction of histones. Acid extraction of histones was prepared from HCT116 $\left(2 \times 10^{6}\right)$ and HT29 $\left(2 \times 10^{6}\right)$ cells, as described previously (8). Cells were washed with PBS and suspended in $10 \mathrm{ml}$ PBS, followed by centrifugation at $200 \mathrm{xg}$ for $10 \mathrm{~min}$ at $4^{\circ} \mathrm{C}$. Cells were then resuspended in $1 \mathrm{ml}$ hypotonic lysis buffer [10 mM Tris- $\mathrm{Cl}\left(\mathrm{pH} \mathrm{8.0),} 1.5 \mathrm{mM} \mathrm{MgCl}_{2}\right.$, $1 \mathrm{mM} \mathrm{KCl}, 1 \mathrm{mM}$ DTT and $1 \mathrm{mM}$ phenylmethylsulfonyl fluoride] and $0.4 \mathrm{~N} \mathrm{H}_{2} \mathrm{SO}_{4}$ at a final concentration of $0.2 \mathrm{M}$, and were lysed on ice for $30 \mathrm{~min}$. After centrifugation at $16,000 \mathrm{x} \mathrm{g}$ for $10 \mathrm{~min}$ at $4^{\circ} \mathrm{C}$, the supernatant fraction that contained the acid-soluble proteins was retained. Trichloroacetic acid $(132 \mu \mathrm{l})$ was added to the supernatant and the samples were incubated on ice overnight. The proteins were then pelleted by centrifugation at $16,000 \mathrm{x}$ for $10 \mathrm{~min}$ at $4^{\circ} \mathrm{C}$, and were washed four times with ice-cold acetone under centrifugation at $16,000 \mathrm{xg}$ for $5 \mathrm{~min}$ at $4^{\circ} \mathrm{C}$. Finally, the histone pellets were air-dried for $20 \mathrm{~min}$ at room temperature and were dissolved in an appropriate volume of $\mathrm{ddH}_{2} \mathrm{O}$. The subsequent histone solution underwent western blotting.

Apoptosis assay. An apoptosis assay was performed using Annexin V/propidium iodide (PI) double staining, according to the manufacturer's protocol (BD Biosciences, Franklin Lakes, NJ, USA). After treatment, the cells were trypsinized and stained with $0.5 \mathrm{mg} / \mathrm{ml} \mathrm{Annexin} \mathrm{V}$ in binding buffer (10 $\mathrm{mM}$ HEPES free acid, $0.14 \mathrm{M} \mathrm{NaCl}$ and $2.5 \mathrm{mM} \mathrm{CaCl}_{2}$ ) for $30 \mathrm{~min}$ at room temperature. Subsequently, PI $(5 \mathrm{mg} / \mathrm{ml}$ final concentration) was added, and the cells were incubated for a further $15 \mathrm{~min}$ at room temperature. Cells were then analyzed using a flow cytometer and BD FACSDiva software version 7 (both BD Biosciences).

Western blot analysis. Treated cells were collected and lysed with NP-40 lysis buffer [0.5\% NP-40, $50 \mathrm{mM}$ Tris- $\mathrm{HCl}$ ( $\mathrm{pH} 7.4$ ), $120 \mathrm{mM} \mathrm{NaCl}, 25 \mathrm{mM}$ NaF, $25 \mathrm{mM}$ glycerol phosphate, $1 \mathrm{mM}$ EDTA, $5 \mathrm{mM}$ EGTA, $1 \mathrm{mM}$ PMSF and $1 \mathrm{mM}$ bezamidine]. Protein concentration was measured using a bicinchoninic acid kit (Pierce; Thermo Fisher Scientific, Inc.). Cell lysates containing 50-80 $\mu \mathrm{g}$ total protein were subjected to $8-15 \%$ SDS-PAGE. Western blotting was performed as described previously (8). The membranes were blocked for $1 \mathrm{~h}$ in PBS containing $0.1 \%$ Tween-20 and $10 \%$ (v/v) skim milk (BioRad Laboratories, Inc., Hercules, CA, USA) and incubated overnight at $4^{\circ} \mathrm{C}$ with primary antibodies (1:500-1:2,000). The following primary antibodies were used. Acetylated- $\alpha$-tubulin (clone number, DM1A; T6793-2ML; 1:2,000) was purchased from Sigma-Aldrich (Merck KGaA). Protein kinase B (AKT; H-136, sc-8312; 1:1,000), phosphorylated (p)-AKT (Ser473, 
sc-7985; 1:500), B-cell lymphoma (Bcl)-2 homologous antagonist/killer (Bak; G-23, sc-832; 1:1,000), extracellular signal-regulated kinase (ERK; K-23, sc-94; 1:1,000), HDAC6 (H-300, sc-11420; 1:1,000) and $\alpha$-tubulin (sc-32293; 1:2,000) were obtained from Santa Cruz Biotechnology, Inc. (Dallas, TX, USA). Anti-poly (ADP-ribose) polymerase (PARP; 551024; 1:1,000) was purchased from BD Biosciences. Bcl-extra large protein (Bcl-xL; 2762; 1:500), caspase-3 (9662S; 1:1,000), p-ERK (Thr202/Tyr204; 4376; 1:1,000), signal transducer and activator of transcription 3 (STAT3; 12640; 1:1,000), and p-STAT3 (Y705, 9138; 1:500) were obtained from Cell Signaling Technology, Inc. (Danvers, MA, USA). Acetylated-histone H3 (06-599, 1:1,000) and histone H3 $(06-755 ; 1: 500)$ antibodies were obtained from EMD Millipore (Billerica, MA, USA). Anti-programmed death-ligand 1 (PD-L1) antibody (PA5-28115; 1:1,000) was purchased from Invitrogen; Thermo Fisher Scientific, Inc. The membranes were then washed with $0.1 \%$ Tween-20/ PBS and incubated at room temperature for $1 \mathrm{~h}$ with horseradish peroxidase-conjugated anti-rabbit (111-035-003; $1: 5,000)$ and anti-mouse $(115-035-003 ; 1: 10,000)$ secondary antibodies (Jackson ImmunoResearch Laboratories, Inc., West Grove, PA, USA). The bound antibodies were detected using an enhanced chemiluminescence western blot analysis system (NCI4080KR, Thermo Fisher Scientific, Inc.) and the blots were semi-quantified using FusionCapt software version 16.08a (Viber Lourmat Sté, Collégien, France).

Drug combination analysis. For combined drug analysis, a constant ratio of ACY-1215 and anticancer agents was evaluated. Drug dilutions and combinations were prepared in media immediately prior to use. Cells ( $3 \times 10^{3} /$ well) in 96 -well plates were incubated with the drugs for $72 \mathrm{~h}$ at $37^{\circ} \mathrm{C}$. A CCK-8 assay was performed to determine cell viability. Drug interactions were determined according to the combination index (CI) method described by Chou (22); CI $>1$ implies antagonism, $\mathrm{CI}=1$ is additive and $\mathrm{CI}<1$ implies synergism. CIs for the combination treatment groups were generated using CalcuSyn software version 2.11 (Biosoft, Cambridge, UK). The fraction affected (FA) was calculated from the percent viability, as follows: $\mathrm{FA}=(100$ - percentage viability $) / 100$.

Statistical analysis. Statistical analyses were conducted using GraphPad Prism software version 5.01 (GraphPad Software, Inc.). All data are presented as the means \pm standard deviation of more than three independent experiments. Statistical differences were determined by Student's t-test or one-way analysis of variance with post hoc analysis using Tukey's multiple comparison test. $\mathrm{P}<0.05$ was considered to indicate a statistically significant difference.

\section{Results}

ACY-1215 selectively inhibits HDAC6 in CRC cells. To the best of our knowledge, ACY-1215 is the first oral selective HDAC6 inhibitor to be studied clinically for hematological cancers (13). To confirm the specific inhibitory effects of ACY-1215 on HDAC6 activity in solid tumors, the present study evaluated its effects on the acetylation of $\alpha$-tubulin (a substrate of HDAC6) and histone H3 (a substrate of class I
Table I. Inhibitory effects of ACY-1215 on the growth and viability of CRC cell lines.

\begin{tabular}{lccc}
\hline & & \multicolumn{2}{c}{$\mathrm{ACY}-1215(\mu \mathrm{M})$} \\
\cline { 3 - 4 } Cell line & Time $(\mathrm{h})$ & $\mathrm{GI}_{50}$ & $\mathrm{IC}_{50}$ \\
\hline \multirow{2}{*}{ HCT116 } & 48 & 1.386 & 1.441 \\
& 72 & 1.368 & 1.164 \\
HT29 & 48 & 5.668 & 5.051 \\
& 72 & 3.804 & 3.683 \\
\hline
\end{tabular}

$\mathrm{GI}_{50}$, drug concentration that inhibited $50 \%$ of cell growth; $\mathrm{IC}_{50}$, drug concentration that inhibited $50 \%$ of cell viability.

HDACs). Human CRC HCT116 and HT29 cells were cultured with an increasing dose of ACY-1215 for $24 \mathrm{~h}$. In HCT116 cells, a dose-dependent increase in acetylated- $\alpha$-tubulin was observed following treatment with low doses $(0.01 \mu \mathrm{M})$ of ACY-1215, without affecting acetylation of histone $(<1 \mu \mathrm{M})$, confirming a greater selective inhibitory effect on HDAC6 activity (Fig. 1A). Higher acetylation selectivity for $\alpha$-tubulin was observed in HCT116 cells $(0.01 \mu \mathrm{M})$ compared with HT29 cells $(0.2 \mu \mathrm{M})$ (Fig. 1B), indicating that ACY-1215 may exert differential HDAC6-inhibitory effects in different CRC cells. To determine the selectivity of ACY-1215 for HDAC6 over class I HDACs, we compared the concentration required to increase acetylated levels of $\alpha$-tubulin compared with that required to increase acetylated levels of histone H3. Levels of acetylated- $\alpha$-tubulin and acetylated-H3 were semi-quantified relative to $\alpha$-tubulin and histone $\mathrm{H} 3$, respectively, and a $>2$-fold increase in acetylated levels was considered to indicate a significant inhibitory effect. Based on western blotting, ACY-1215 was $\sim 5$-fold (HDAC6 inhibitory concentration, $0.2 \mu \mathrm{M}$; vs. class I HDAC inhibitory concentration, $1 \mu \mathrm{M})$ and 100 -fold (0.01 vs. $1 \mu \mathrm{M})$ less active against class I HDACs in HT29 and HCT116 cells, respectively (Fig. 1A and B). The pan-HDAC inhibitor, SAHA, was used as a positive control for HDAC inhibition (23). These results indicated that ACY-1215 may be a selective HDAC6 inhibitor with minimal class I HDAC activity in CRC cells.

ACY-1215 induces time- and dose-dependent cytotoxicity in CRC cells. The present study examined the effects of ACY-1215 on cell growth and viability in HCT116 and HT29 CRC cells. Cells were cultured with ACY-1215 for up to $72 \mathrm{~h}$, and cell growth and viability were assessed using CCK-8 assays. Compared with the control cells, ACY-1215 treatment resulted in a time- and dose-dependent decrease in the growth and viability of CRC cells, with $\mathrm{GI}_{50}$ values between 1.37 and $5.67 \mu \mathrm{M}$, and $\mathrm{IC}_{50}$ values between 1.16 and $5.05 \mu \mathrm{M}$ (Fig. 1C-F and Table I). Taken together, these findings suggested that selective inhibition of HDAC6 by ACY-1215 may result in inhibition of the growth and viability of CRC cells.

Combined treatment of ACY-1215 with an anticancer agent efficiently induces apoptosis of CRC cells. Based on prior evidence confirming the efficacy of ACY-1215 and proteasome 
A

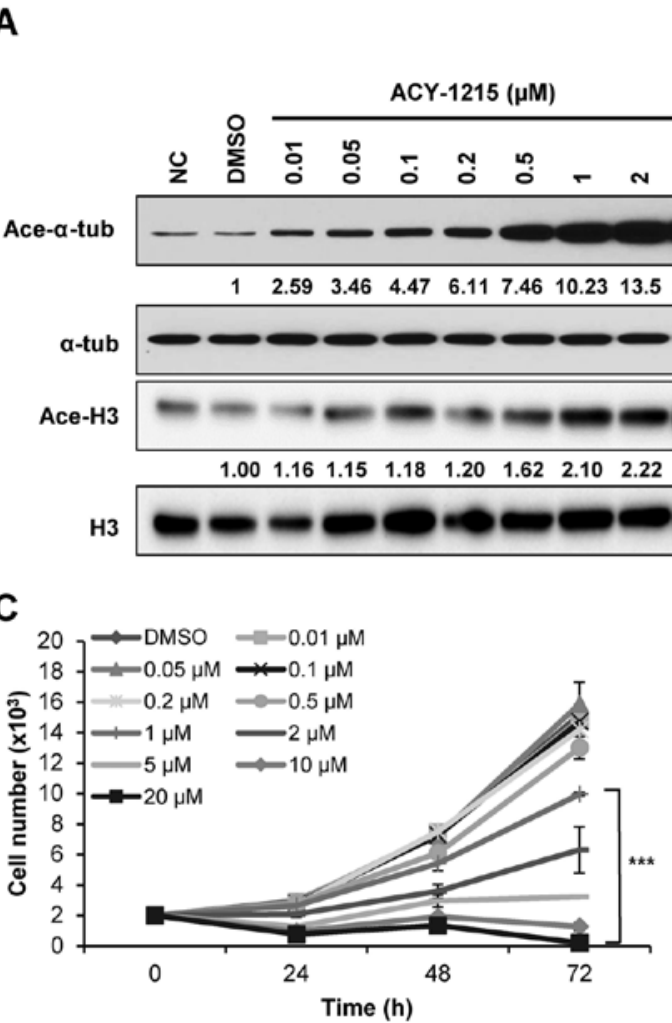

B

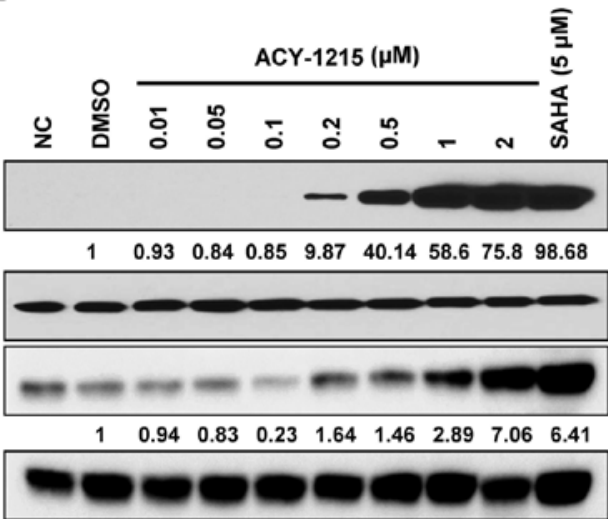

C

E

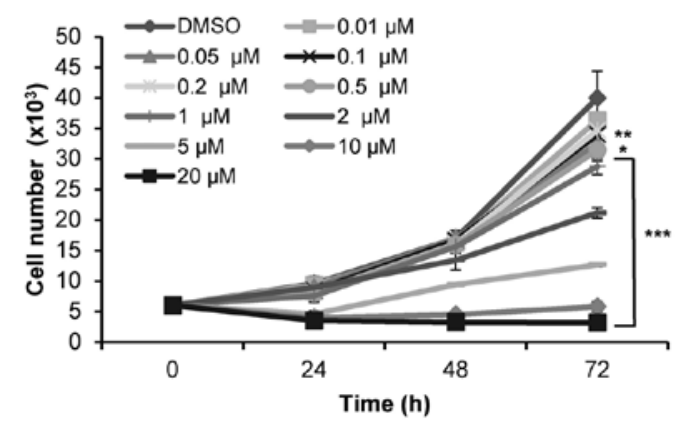

D

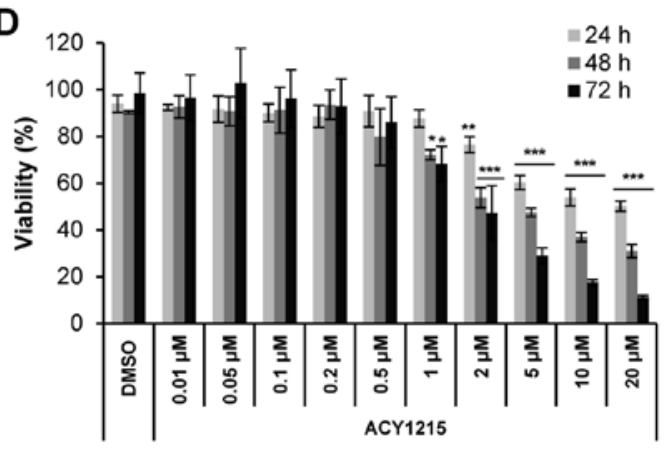

$\mathbf{F}$

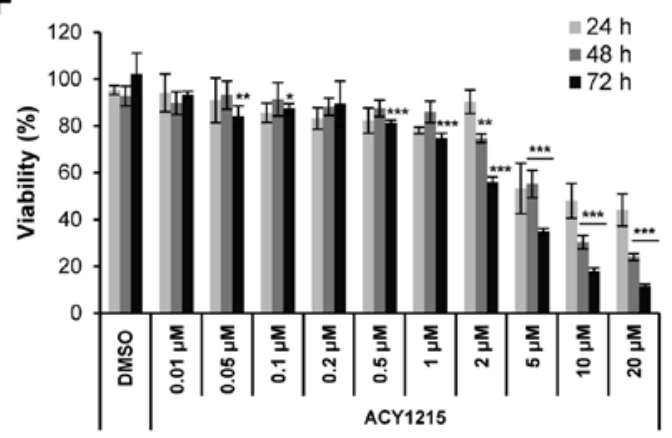

Figure 1. ACY-1215, an HDAC6 inhibitor with minimal effects on class I HDACs, suppresses the growth and viability of CRC cells. (A) HCT116 and (B) HT29 cells were treated with ACY-1215 at the indicated concentrations for $24 \mathrm{~h}$, and western blot analysis was performed using antibodies against Ace- $\alpha$-tub, Ace-H3, $\alpha$-tub and total H3. Levels of Ace- $\alpha$-tub and Ace-H3 were semi-quantified relative to $\alpha$-tub and H3, respectively, and the levels in the $0.1 \%$ DMSOtreated groups were set at $1 . \alpha$-tub and histone $\mathrm{H} 3$ were used as equal loading controls. The pan-HDAC inhibitor, SAHA, was used as a positive control for HDAC inhibition. Cell growth and viability of (C and E) HCT116 and (D and F) HT29 cells cultured with $0.1 \%$ DMSO (control) or ACY-1215 at the indicated concentrations $(0.01,0.05,0.1,0.2,0.5,1,2,5,10$ and $20 \mu \mathrm{M})$ for $72 \mathrm{~h}$. Viable cell numbers and viability were measured using CCK-8 assays. Cell counts were estimated indirectly from a standard curve generated using solutions of known cell counts. Absorbance was normalized to that of the negative control at each time interval. Data are expressed as the means \pm standard deviation from three independent experiments. ${ }^{*} \mathrm{P}<0.05$, ${ }^{* *} \mathrm{P}<0.01$ and ${ }^{* * *} \mathrm{P}<0.001 \mathrm{vs}$. the $\mathrm{DMSO}$ control or as indicated; analysis of variance test. Ace-, acetylated; $\alpha$-tub, $\alpha$-tubulin; CCK-8, Cell Counting kit-8; CRC, colorectal cancer; DMSO, dimethyl sulfoxide; H3, histone $\mathrm{H} 3$; NC, negative control; SAHA, suberoylanilide hydroxamic acid.

inhibitors or immunomodulatory drugs for the treatment of hematopoietic malignancies $(13,24-27)$, the present study aimed to identify effective therapeutic combinations of ACY-1215 with conventional therapeutic drugs in CRC cells. CRC cells were treated with either ACY-1215 alone or in combination with conventional anticancer drugs, including the topoisomerase I inhibitor irinotecan, the DNA synthesis inhibitor 5-FU, and the DNA-damaging agent oxaliplatin. Cells then were analyzed by western blotting to detect apoptosis. A previous study demonstrated that in HCT116 and HT29 cells cultured with $2 \mu \mathrm{M}$ ACY-1215, the expression levels of PARP and caspase-3, and the Bak to Bcl-xL ratio, remained unchanged (27). In the present study, cells cultured with a combination of ACY-1215 and oxaliplatin or irinotecan exhibited a synergistic increase in cleaved PARP and active caspase-3 expression compared with in the single agent-treated groups (Fig. 2A and B). The expression levels of the proapoptotic molecule Bak were additively increased, whereas the expression levels of the anti-apoptotic molecule Bcl-xL were additively decreased in both cell lines when ACY-1215 was combined with either 5-FU, oxaliplatin or irinotecan compared with the anticancer compound alone (Fig. 2A and B). Furthermore, Annexin V/PI staining revealed that cell apoptosis was significantly increased following combination treatment of cells with ACY-1215 and anticancer drugs (Fig. 2C and D). Overall, these results suggested that 
A

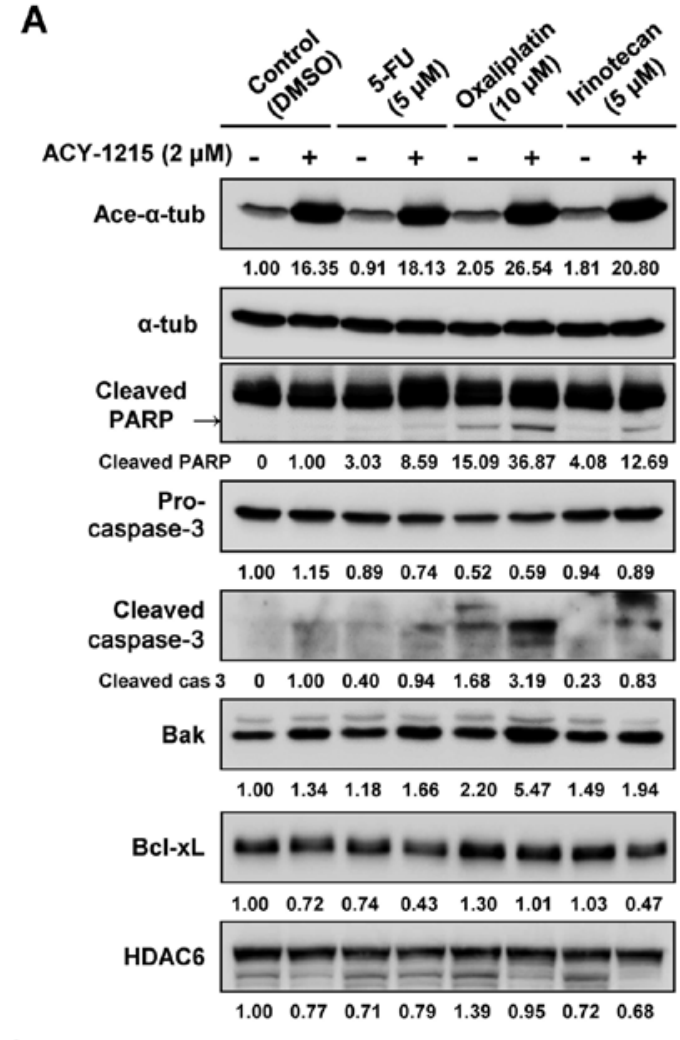

C

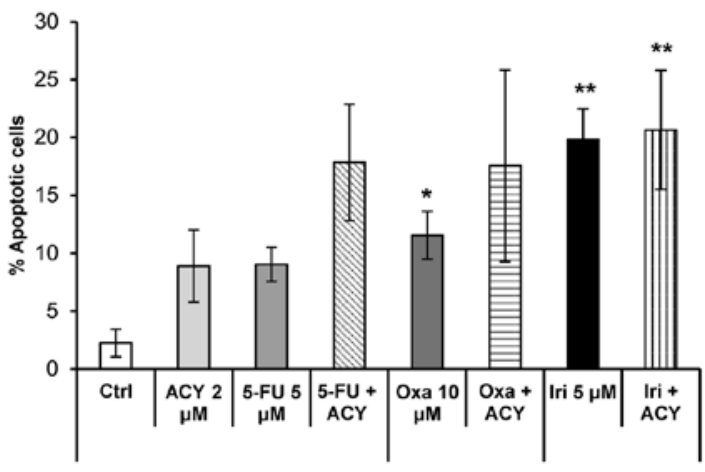

B

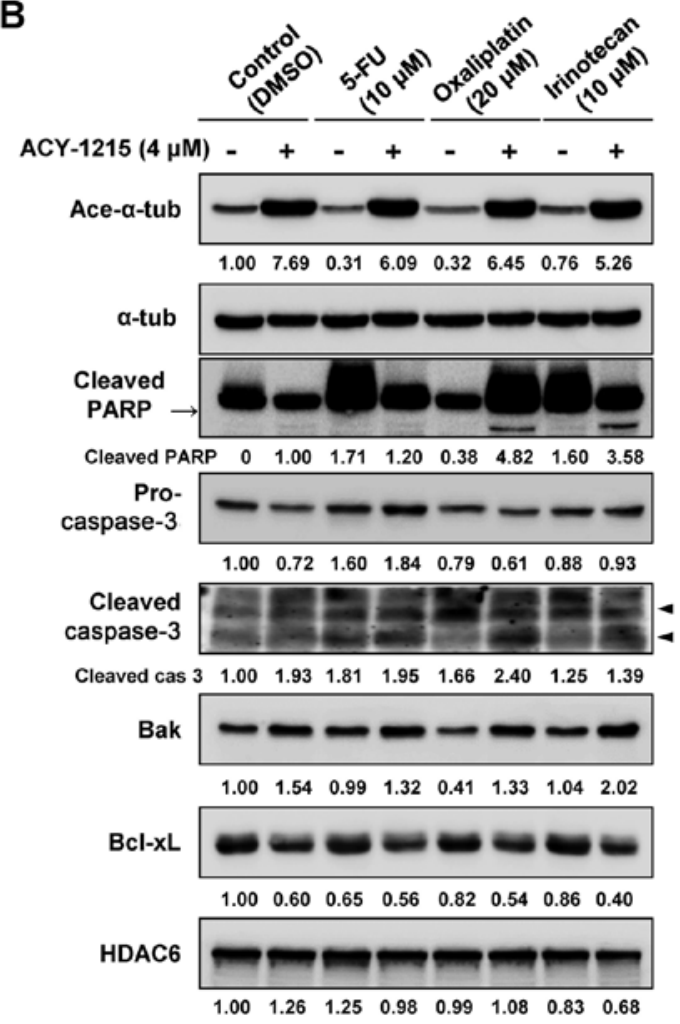

D

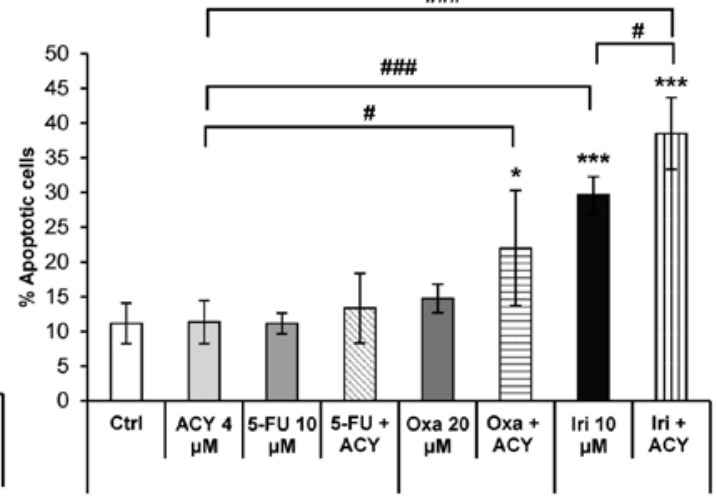

Figure 2. ACY-1215 synergistically increases apoptosis induced by anticancer agents. (A) HCT116 and (B) HT29 cells were treated with 0.1\% DMSO (control), ACY-1215, 5-FU, oxaliplatin, irinotecan or a combination of these compounds for $24 \mathrm{~h}$. Western blot analysis was performed using the indicated antibodies. The protein expression levels were semi-quantified relative to $\alpha$-tub; the levels in the 0.1\% DMSO group or ACY-1215-treated group (cleaved PARP and cleaved caspase-3) were set at 1 . $\alpha$-tub was used as a loading control. (C) HCT116 and (D) HT29 cells were treated with the indicated compounds for 48 h and stained with Annexin V and propidium iodide for $15 \mathrm{~min}$. Apoptosis induced by these compounds was assessed by flow cytometry ( $\mathrm{n}=3$ ). Data are presented as the means \pm standard deviation from three independent experiments. ${ }^{*} \mathrm{P}<0.05,{ }^{* *} \mathrm{P}<0.01$ and ${ }^{* * * *} \mathrm{P}<0.001$ vs. the $\mathrm{DMSO}$ control; ${ }^{\#} \mathrm{P}<0.05,{ }^{\# \#} \mathrm{P}<0.01$ and ${ }^{\# \# \#} \mathrm{P}<0.001$ vs. single agent-treated group, analysis of variance test. 5-FU, 5-fluorouracil; $\alpha$-tub, $\alpha$-tubulin; Ace-, acetylated; ACY, ACY-1215; Bak, Bcl-2 homologous antagonist/killer; Bcl, B-cell lymphoma; Bcl-xL, Bcl-extra large protein; Ctrl, control; DMSO, dimethyl sulfoxide; HDAC6, histone deacetylase 6; Iri, irinotecan; Oxa, oxaliplatin; PARP, poly (ADP-ribose) polymerase.

ACY-1215 alone may not efficiently induce apoptosis in solid tumors; however, combination treatment of ACY-1215 with anticancer drugs may trigger apoptosis by activating caspases and downregulating the expression of anti-apoptotic factors.

ACY-1215 in combination with anticancer agents exhibits synergistic cytotoxicity. The present study also detected the combined effects of ACY-1215 and conventional therapeutic drugs on CRC cytotoxicity. Cells were treated with either ACY-1215 alone or in combination with conventional anticancer drugs, and CCK-8 assays were performed to measure cell growth and viability (Fig. 3A-D). Combined treatment resulted in synergistic growth inhibition in both cell lines (Fig. 3A and C). The combination of ACY-1215 with 5-FU, oxaliplatin or irinotecan increased cell death compared with treatment with the anticancer agent alone in HCT116 and HT29 cells (Fig. 3B and D). To further confirm the synergistic interaction between ACY-1215 and anticancer drugs, synergism was evaluated according to the Chou and Talalay method (22). The combination of ACY-1215 and 5-FU, oxaliplatin or irinotecan exhibited moderately synergistic anticancer activities with $\mathrm{CI}<1.0$ in HT29 cells. However, ACY-1215 had no detectable synergistic effect on cell viability when combined with all three anticancer agents in HCT116 cells (Fig. 3E and F; 
A

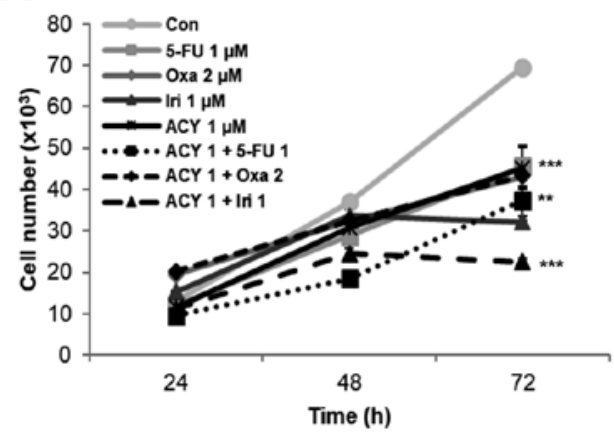

C

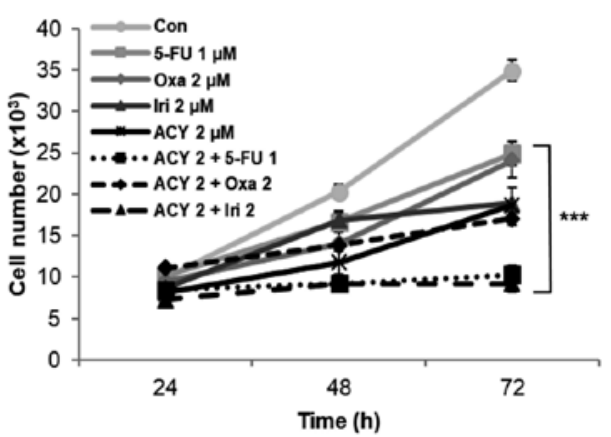

E

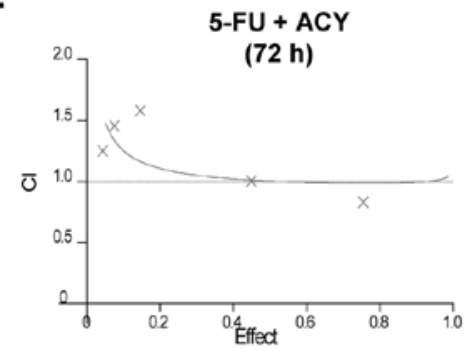

$\mathbf{F}$

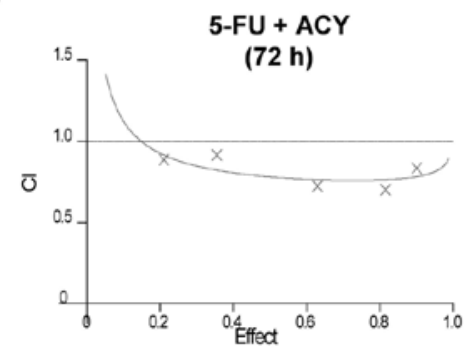

B
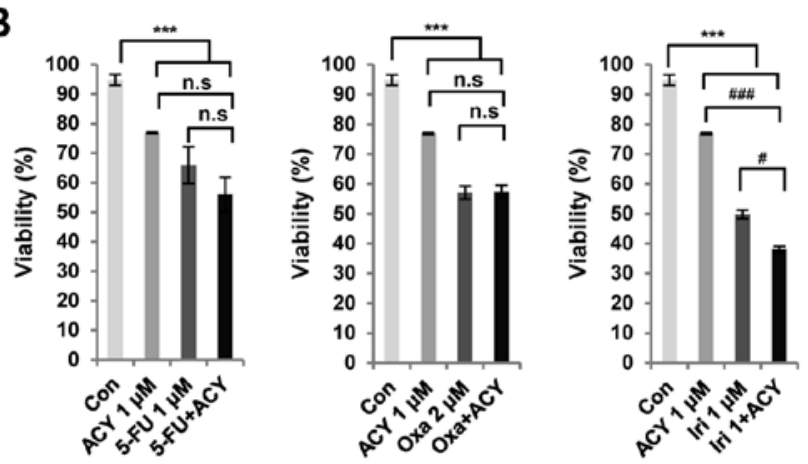

D
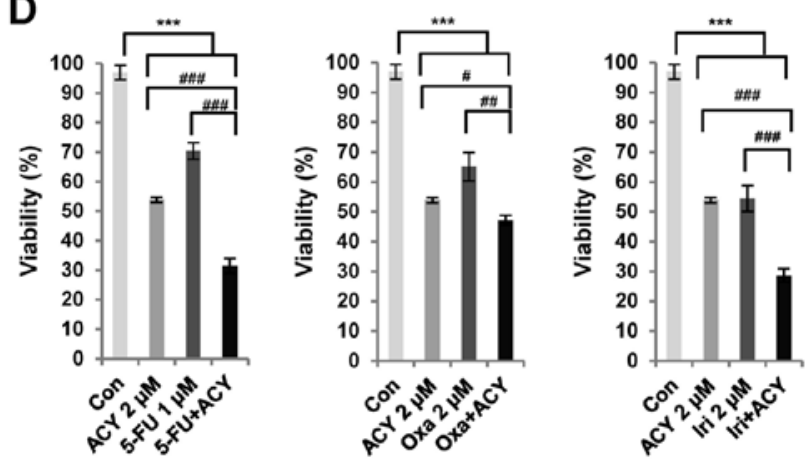

Oxa + ACY
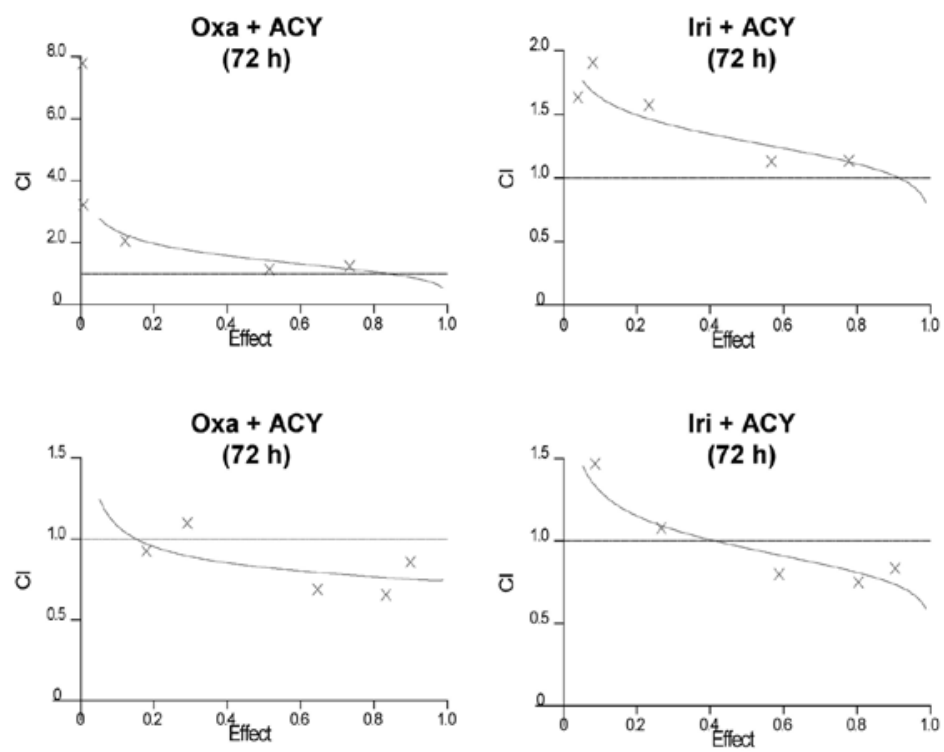

Figure 3. Combined treatment of ACY-1215 and anticancer agents triggers synergistic cytotoxicity. (A and B) HCT116 and (C and D) HT29 cells were treated with $0.1 \%$ DMSO (control) or the indicated compounds alone or in combination for $72 \mathrm{~h}$. Cell growth (24-72 h) and viability (72 h) were measured by CCK-8 assays. Cell counts were indirectly estimated from a standard curve generated using solutions of known cell counts. The CI and $\mathrm{F}_{\mathrm{A}}$ of ACY-1215 and anticancer agents in (E) HCT116 and (F) HT29 cells. Cells maintaining a constant ratio between the dose of ACY-1215 and 5-FU, oxaliplatin or irinotecan, and cell viability were assessed at $72 \mathrm{~h}$ using the CCK-8 assay. The CI value and the relative $\mathrm{F}_{\mathrm{A}}$ were determined at each dose combination (actual), and simulations were run to estimate the $\mathrm{CI}$ value and confidence interval across the entire $\mathrm{F}_{\mathrm{A}}$ range (simulation). $\mathrm{CI}<1, \mathrm{CI}=1$ and $\mathrm{CI}>1$ indicate synergistic, additive and antagonistic effects, respectively. Data are presented as the means \pm standard deviation from three independent experiments. ${ }^{*} \mathrm{P}<0.05,{ }^{* *} \mathrm{P}<0.01$ and ${ }^{* * * *} \mathrm{P}<0.001$ vs. the DMSO control; ${ }^{\#} \mathrm{P}<0.05,{ }^{\# \#} \mathrm{P}<0.01$ and ${ }^{\# \# \#} \mathrm{P}<0.001$ vs. the single agent-treated groups; analysis of variance test. 5-FU, 5-fluorouracil; ACY, ACY-1215; $\mathrm{CI}$, combination index; Con, control; $\mathrm{F}_{\mathrm{A}}$, fraction affected; Iri, irinotecan; Oxa, oxaliplatin; $n$.s, not significant.

Table II). These data confirmed the significant potentiation of anti-proliferative effects when two agents were combined in HT29 cells, but not in HCT116 cells.

Inhibition of AKT and ERK contributes to ACY-1215-induced apoptosis. ACY-1215 treatment has previously been reported to slightly decrease phosphorylation of AKT and ERK1/2, without altering total AKT and ERK1/2 expression, in CRC cells (27). To assess synergism at the molecular level, the present study evaluated the expression levels of mitogenactivated protein kinases and AKT signaling pathways in CRC cells (Fig. 4). Consistent with increased apoptosis (Fig. 2), combination treatment with ACY-1215 and 5-FU, oxaliplatin or irinotecan synergistically decreased phosphorylation of 
Table II. Mean CI for cells exposed to various drug combinations.

\begin{tabular}{llccc}
\hline Cell line & \multicolumn{1}{c}{ Drug } & Mean CI value & CI range & Synergy \\
\hline HCT116 & ACY + 5-FU & 1.2246 & $0.832-1.58$ & No synergism \\
& ACY + Oxa & 1.4758 & $1.133-1.908$ & No synergism \\
\multirow{3}{*}{ HT29 } & ACY + Iri & 3.0902 & $1.139-7.789$ & No synergism \\
& ACY + 5-FU & 0.812 & $0.701-0.915$ & Moderate synergism \\
& ACY + Oxa & 0.8454 & $0.654-1.099$ & Moderate synergism \\
& ACY + Iri & 0.9862 & $0.751-1.469$ & Moderate synergism \\
\hline
\end{tabular}

Synergism, $\mathrm{CI}<0.7$; moderate synergism, $\mathrm{CI}=0.7-0.9$; additive effect, $\mathrm{CI}=0.9-1.1$. 5-FU, 5-fluorouracil; ACY, ACY-1215; CI, combination index; Iri, irinotecan; Oxa, oxaliplatin.

A

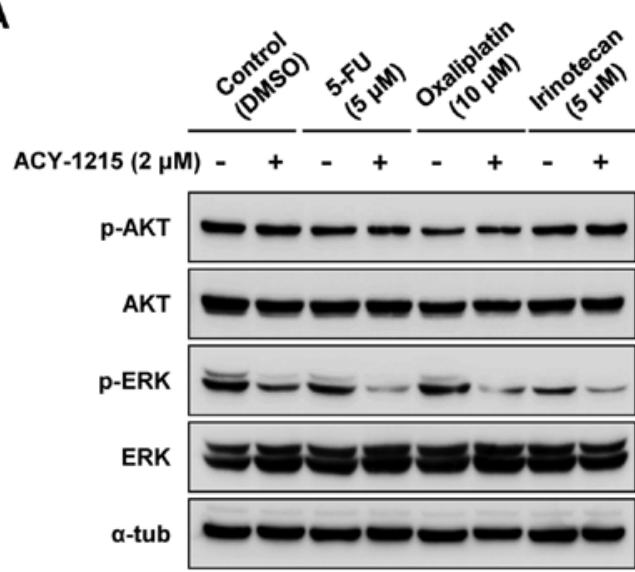

C
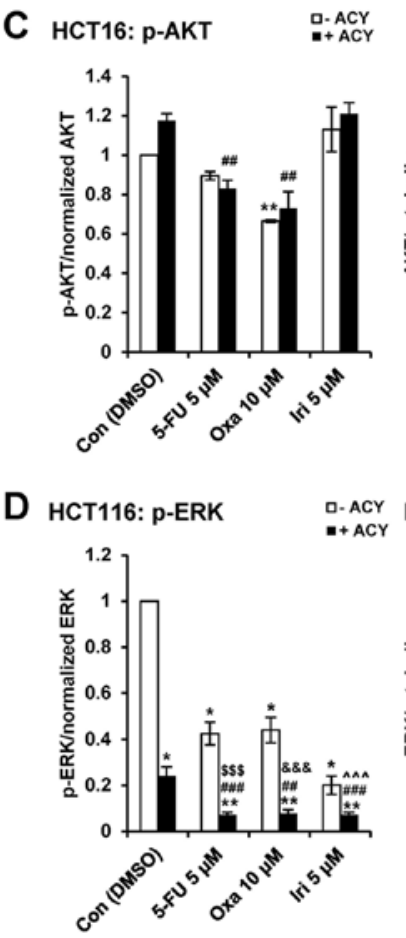
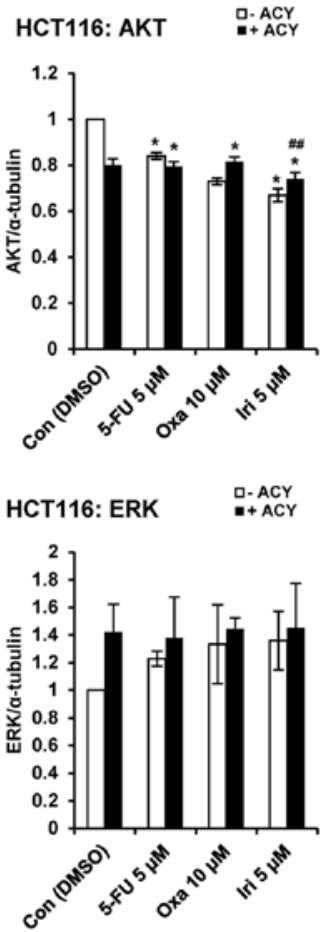

B

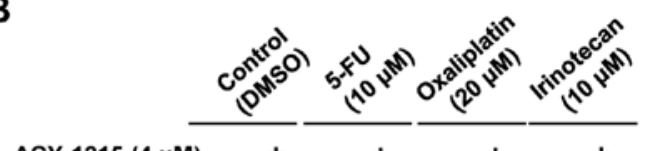

$\operatorname{ACY}-1215(4 \mu \mathrm{M})-+-+-+$
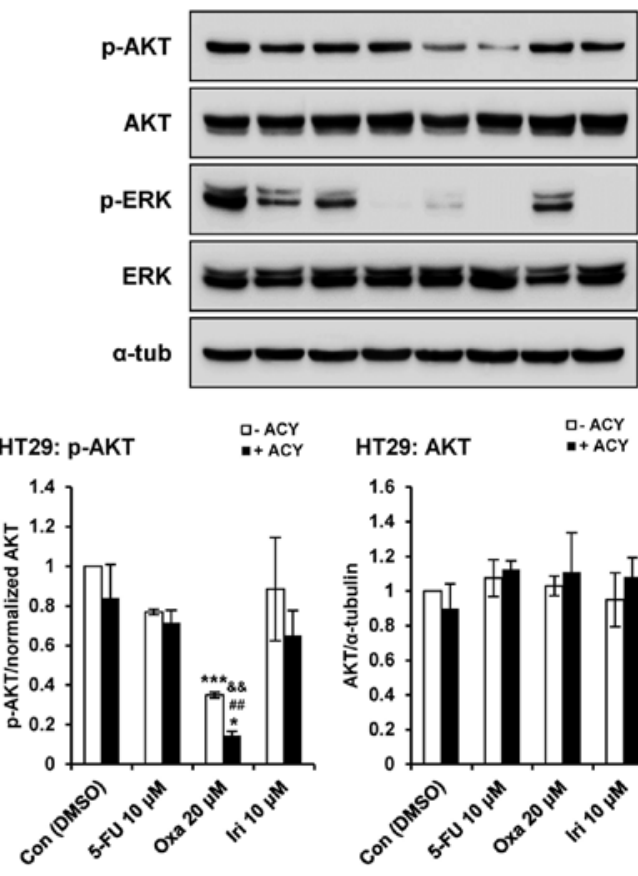

HT29: AKT $\quad \begin{array}{ll}\text { - } A C Y \\ \text { ACY }\end{array}$
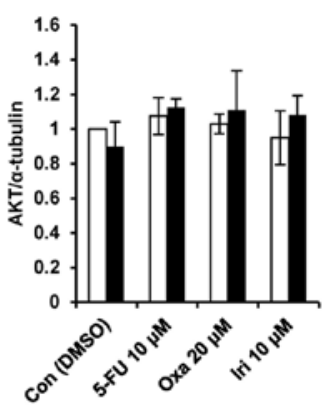

HT29: p-ERK

HT29: ERK $\quad$ D.ACY
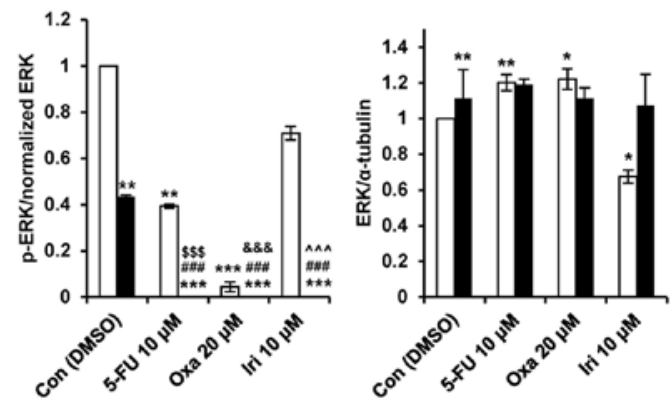

Figure 4. ACY-1215 regulates the AKT and mitogen-activated protein kinases pathways. (A) HCT116 and (B) HT29 cells were treated with 0.1\% DMSO (control), or ACY-1215, 5-FU, oxaliplatin and irinotecan alone or in combination for $24 \mathrm{~h}$. Whole-cell lysates were subjected to western blotting with the indicated antibodies (upper panel). Relative protein expression levels were semi-quantified by densitometric analysis of the blots. Expression levels of (C) p-AKT and (D) p-ERK were semi-quantified relative to AKT and ERK. The abundance of the indicated proteins was semi-quantified relative to $\alpha$-tub; the levels in the $0.1 \%$ DMSO group were set at $1 . \alpha$-tub was used as a loading control. ${ }^{*} \mathrm{P}<0.05,{ }^{* * *} \mathrm{P}<0.01$ and ${ }^{* * *} \mathrm{P}<0.001$ vs. the $\mathrm{DMSO}$ control; ${ }^{\# \#} \mathrm{P}<0.01$ and ${ }^{\# \# \#} \mathrm{P}<0.001$ vs. the ACY-1215-treated group; ${ }^{\$ \$} \mathrm{P}<0.001$ vs. the 5-FU-treated group; ${ }^{\& \&} \mathrm{P}<0.01$ and ${ }^{\& \& \&} \mathrm{P}<0.001$ vs. the oxaliplatin-treated group; ${ }^{\wedge \wedge} \mathrm{P}<0.001$ vs. the irinotecantreated group; analysis of variance test. 5-FU, 5-fluorouracil; $\alpha$-tub, $\alpha$-tubulin; ACY, ACY-1215; AKT, protein kinase B; Con, control; DMSO, dimethyl sulfoxide; ERK, extracellular signal-regulated kinase; Iri, irinotecan; Oxa, oxaliplatin; p-, phosphorylated. 
A

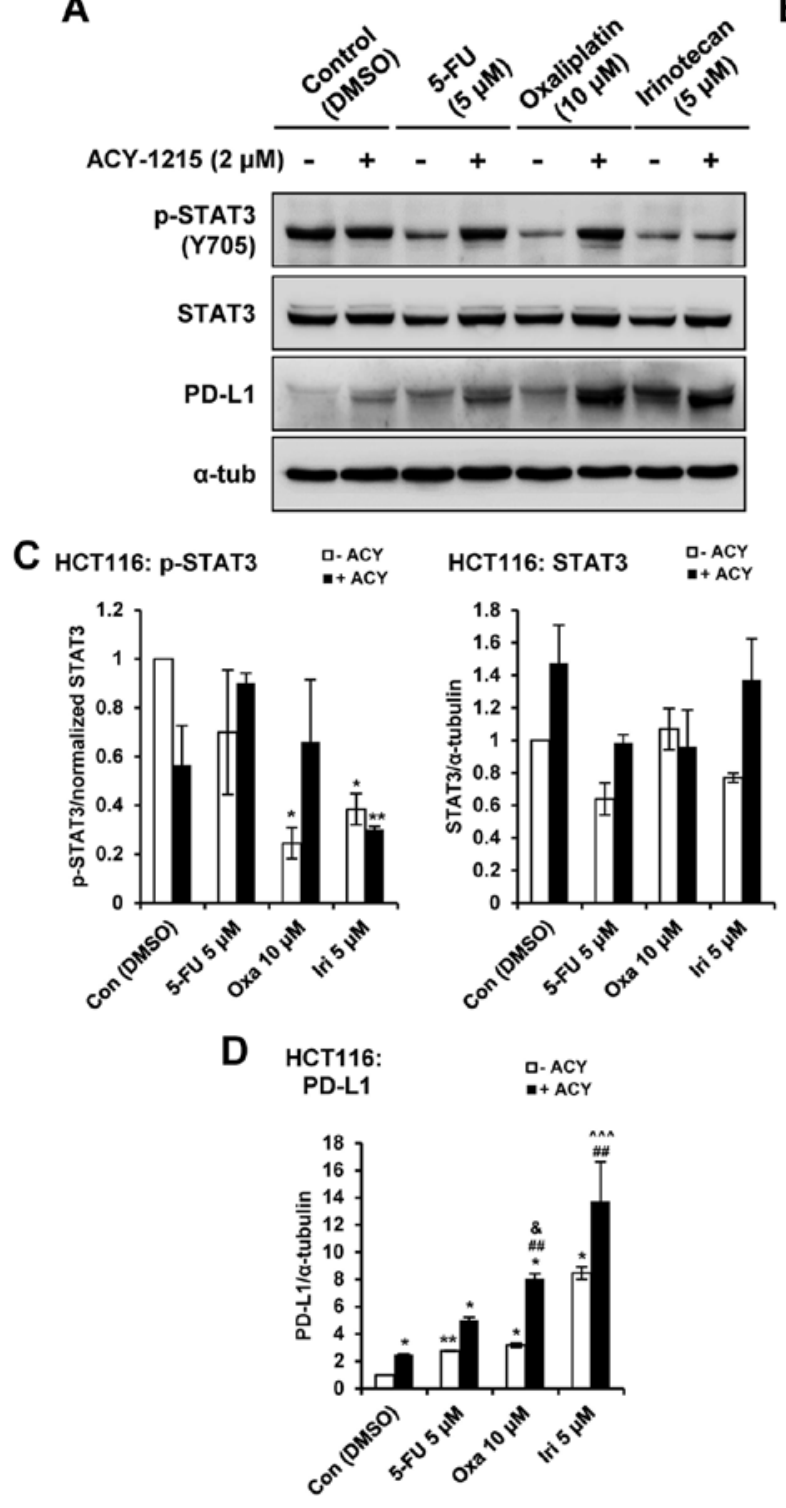

B

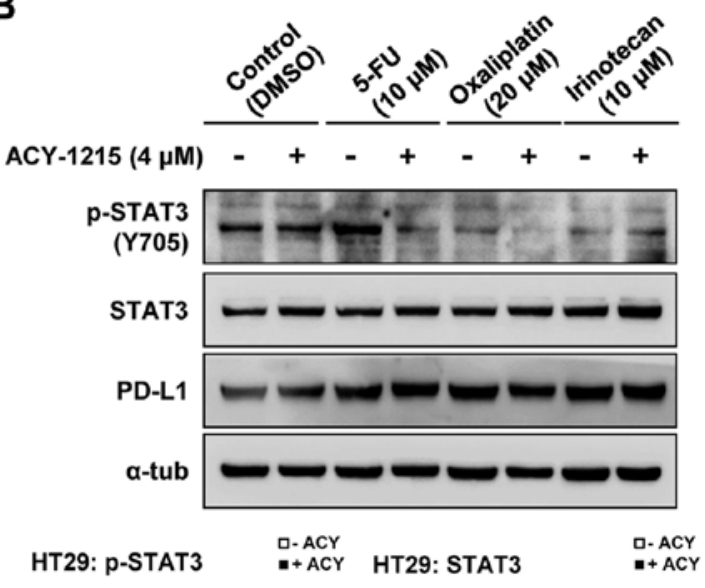

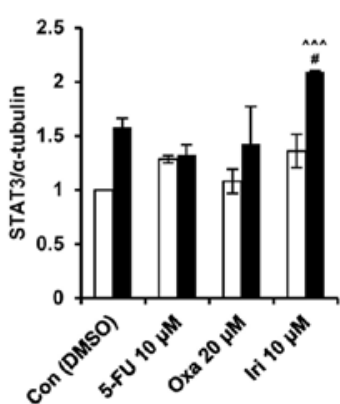

口-ACY + ACY

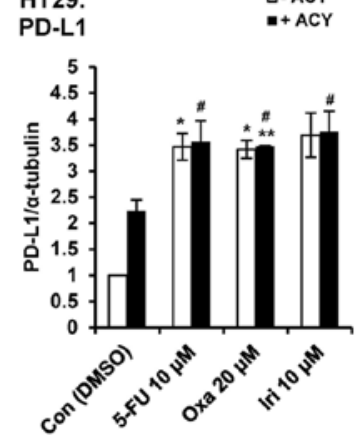

Figure 5. ACY-1215 regulates the STAT and PD-L1 pathway. (A) HCT116 and (B) HT29 cells were treated with 0.1\% DMSO (control), or ACY-1215, 5-FU, oxaliplatin and irinotecan alone or in combination for $24 \mathrm{~h}$. Whole-cell lysates were subjected to western blotting with the indicated antibodies. Relative protein expression levels were semi-quantified by densitometric analysis of the blots. Expression levels of (C) p-STAT3 and (D) PD-L1 were semi-quantified relative to STAT3 and $\alpha$-tub, respectively; the levels in the $0.1 \%$ DMSO group were set at $1 . \alpha$-tub was used as a loading control. ${ }^{*} \mathrm{P}<0.05$ and ${ }^{* *} \mathrm{P}<0.01$ vs. the DMSO control; ${ }^{~} \mathrm{P}<0.05,{ }^{\# \#} \mathrm{P}<0.01$ and ${ }^{\# \# "} \mathrm{P}<0.001$ vs. the ACY-1215-treated group; ${ }^{\$ \$ \$} \mathrm{P}<0.001$ vs. the 5 -FU-treated group; ${ }^{\text {\& }} \mathrm{P}<0.05$ and ${ }^{\text {\&\&\& }} \mathrm{P}<0.001$ vs. the oxaliplatin-treated group; ${ }^{\wedge \wedge} \mathrm{P}<0.001$ vs. the irinotecan-treated group; analysis of variance test. 5-FU, 5-fluorouracil; $\alpha$-tub, $\alpha$-tubulin; ACY, ACY-1215; Con, control; DMSO, dimethyl sulfoxide; Iri, irinotecan; Oxa, oxaliplatin; p-, phosphorylated; PD-L1, programmed death-ligand 1; STAT3, signal transducer and activator of transcription 3 .

ERK1/2 in HCT116 and HT29 cells compared with treatment with the single agents (Fig. 4A, B and D). Combined treatment with ACY-1215 and oxaliplatin synergistically decreased phosphorylation of AKT without changes in total AKT in HT29 cells but not HCT116 cells (Fig. 4A-C). Together, these findings indicated that coadministration of ACY-1215 and anticancer agents may suppress survival signaling pathways in CRC cells.

ACY-1215 in combination with anticancer agents upregulates $P D$-L1 in CRC cells. Our recent report demonstrated that single-agent treatment with ACY-1215 resulted in increased levels of PD-L1, and greater phosphorylation of STAT3 in CRC cells (27). Therefore, the present study aimed to determine whether combined treatment with ACY-1215 and anticancer agents could modulate the expression of PD-L1 and the phosphorylation of STAT3 in CRC cells. Combination treatment with ACY-1215 and 5-FU, oxaliplatin or irinotecan decreased the phosphorylation of STAT3 in HT29, but not HCT116 cells, compared with in the single agent-treated groups (Fig.. 5A-C). Combination treatment with ACY-1215 and oxaliplatin or irinotecan enhanced the expression levels of PD-L1 in HCT116 compared with in the single agent-treated groups in a STAT3-independent manner in HCT116 cells (Fig. 5A-D). Treatment with the four single agents caused an increase in PD-L1 levels irrespective of p-STAT3; however, combination treatment did not induce synergistic effects in HT29 cells. These results indicated that HDAC6 may regulate 
the expression levels of PD-L1 and serve an important role in immune-related pathways in CRC cells.

\section{Discussion}

HDACs are key epigenetic regulators that are considered promising therapeutic targets for cancer treatment. HDAC inhibitors (HDACis) kill tumor cells via numerous mechanisms, including DNA repair inhibition, cell-cycle checkpoint disruption and the induction of apoptosis $(28,29)$. HDACis represent a chemically diverse group of drugs that affect cancer, which are currently at various stages of development. At present, two HDACis, vorinostat and romidepsin, have been approved by the United States Food and Drug Administration for the treatment of cutaneous $\mathrm{T}$ cell lymphoma. In addition, belinostat has recently been approved for the treatment of peripheral $\mathrm{T}$ cell lymphoma, and panobinostat has been approved for the treatment of MM. In addition, $>100$ clinical trials have been initiated with HDACis used as a monotherapy or in combination therapy (30). However, pan-HDACis elicit profound side effects, including fatigue, nausea, vomiting, diarrhea, thrombocytopenia and neutropenia, because they target several HDAC isoforms. Therefore, more tolerable HDAC is are required, with HDAC6-selective inhibitors considered promising agents that avoid the toxicity that is associated with class I HDACis $(9,31)$.

ACY-1215 (ricolinostat) is a leading HDAC6 inhibitor, which is currently being tested in advanced clinical trials for hematological cancer (myeloma and lymphoid malignancies) $(13,18-21)$. Ricolinostat is well tolerated and is the only clinically tested HDAC6-selective inhibitor. In addition, ricolinostat has been analyzed in a phase I/II clinical trial as a monotherapy, and in combination with bortezomib and dexamethasone in MM (NCT01323751). At the recommended phase II dose of $160 \mathrm{mg} /$ day ricolinostat, the combination with bortezomib and dexamethasone is safe, well-tolerated and active in MM (19). Ricolinostat has also been evaluated in a phase I/II clinical trial in combination with lenalidomide and dexamethasone, in order to determine the maximum tolerated dose when used in combination therapy (NCT01583283). The phase Ib study provides preliminary evidence that ricolinostat in combination with lenalidomide and dexamethasone is safe and well-tolerated in R/R MM (20). An additional phase Ib/II clinical trial aims to determine the optimal dosing of ricolinostat when combined with pomalidomide and dexamethasone. The phase II study among patients with R/R MM aims to determine the overall response rate of this combination (NCT01997840). Finally, a phase Ib study in patients with $\mathrm{R} / \mathrm{R} \mathrm{MM}$ aims to determine the maximum tolerated dose and safety of a liquid formulation of ricolinostat used in combination with pomalidomide and low-dose dexamethasone (NCT02189343).

Unlike hematological malignancies, ricolinostat is a single agent that exhibits limited anticancer activity in solid tumors, as confirmed in our previous study, which indicated that ricolinostat at low doses is unable to decrease viability and to induce apoptosis (27). Although HDACis alone may be clinically useful, they too are most often used in combination with other anticancer agents for cancer treatment. Synergistic interactions between oxaliplatin and the HDACis, MS275, suberoyl bishydroxamic acid and SAHA, have been reported in CRC cells $(32,33)$. Oxaliplatin is a chemotherapeutic agent approved for use in the treatment of numerous types of solid tumor; however, incomplete clinical responses are commonly observed. Therefore, there is a need to enhance therapeutic activity in the form of novel drugs that are well tolerated in combination with oxaliplatin. The present study demonstrated that synergistic CRC cell cytotoxicity was triggered by ricolinostat when used in combination with oxaliplatin; ricolinostat enhanced the oxaliplatin-induced inhibition of cell viability. Furthermore, the increased caspase and PARP cleavage observed following combined drug treatment confirmed that the apoptotic response was enhanced following combination therapy. To further confirm these in vitro results, a future in vivo study is required. Consistent with these results, Wang et al reported that ricolinostat inhibits the proliferation of glioblastoma, induces apoptosis at high doses and sensitizes glioblastoma cells to temozolomide (34). ACY-241 is a second-generation orally available selective HDAC6 inhibitor that is structurally related to ACY-1215. Recently, ACY-241 treatment with paclitaxel was revealed to suppress cancer cell proliferation and increase cell death relative to either single agent (35). Overall, these findings provide a direct rationale for the use of ricolinostat as a therapeutic agent for the treatment of patients with solid tumors, in addition to blood cancers.

In conclusion, the present study identified ACY-1215 as an HDAC6 inhibitor that potentiated the anticancer drug efficacy of certain chemotherapeutic drugs; however, the use of ACY-1215 as a single agent in CRC was not potent or efficient. A predominant downregulation of p-ERK and p-AKT was detected in CRC cells following combined treatment with ACY-1215 and anticancer drugs. Furthermore, combined treatment effectively induced CRC cell apoptosis via activation of caspase- 3 and elevation of the Bak to $\mathrm{Bcl}-\mathrm{xL}$ ratio. Taken together, these data indicated that an HDAC6-selective inhibitor may be able to significantly augment chemotherapeutic drug-mediated anticancer effects. ACY-1215 increased the expression levels of PD-L1 independent of the STAT3 pathway. Although little is currently known regarding the molecular mechanism by which HDAC6 regulates the expression and stability of PD-L1, combination treatment with ACY-1215 and other anticancer agents markedly upregulated PD-L1 expression in CRC cells. These results strongly suggested that a combination of ACY-1215 and other chemotherapeutic agents could be beneficial for treating CRC by modulating PD-L1. Therefore, we aim to conduct further studies regarding the underlying molecular mechanisms. The present results suggested that ACY-1215 in combination with oxaliplatin may be considered a valuable novel treatment for patients with CRC. ACY-1215 is currently undergoing clinical trials, and data from phase I studies exist with regards to maximum tolerated doses, toxicity, and pharmacokinetic and pharmacodynamic information. Collectively, the present findings may inform clinical trials of the efficiency of combination chemotherapy containing a HDAC6-selective inhibitor.

\section{Acknowledgements}

Not applicable. 


\section{Funding}

The present study was supported by the Basic Science Research Program through the National Research Foundation of Korea funded by the Ministry of Education, Science and Technology (grant no. 2016R1D1A1A02937071).

\section{Availability of data and materials}

The datasets used and/or analyzed during the current study are available from the corresponding author on reasonable request.

\section{Authors' contributions}

DHL designed and performed the experiments, and analyzed the data. HRW and HWR performed the experiments. JMH analyzed some data and helped to edit the manuscript. SHK conceived the general design of the study, wrote the initial draft of the manuscript, extensively edited the manuscript and supervised the work.

\section{Ethics approval and consent to participate}

Not applicable.

\section{Consent for publication}

Not applicable.

\section{Competing interests}

The authors declare that they have no competing interest.

\section{References}

1. Jemal A, Center MM, DeSantis C and Ward EM: Global patterns of cancer incidence and mortality rates and trends. Cancer Epidemiol Biomarkers Prev 19: 1893-1907, 2010.

2. Siegel R, Naishadham D and Jemal A: Cancer statistics, 2013. CA Cancer J Clin 63: 11-30, 2013.

3. Hubbert C, Guardiola A, Shao R, Kawaguchi Y, Ito A, Nixon A, Yoshida M, Wang XF and Yao TP: HDAC6 is a microtubule-associated deacetylase. Nature 417: 455-458, 2002.

4. Zhang Y, Gilquin B, Khochbin S and Matthias P: Two catalytic domains are required for protein deacetylation. J Biol Chem 281: 2401-2404, 2006.

5. Li Y, Shin D and Kwon SH: Histone deacetylase 6 plays a role as a distinct regulator of diverse cellular processes. FEBS J 280 : 775-793, 2013.

6. Boyault C, Zhang Y, Fritah S, Caron C, Gilquin B, Kwon SH, Garrido C, Yao TP, Vourc'h C, Matthias P, et al: HDAC6 controls major cell response pathways to cytotoxic accumulation of protein aggregates. Genes Dev 21: 2172-2181, 2007.

7. Kawaguchi Y, Kovacs JJ, McLaurin A, Vance JM, Ito A and Yao TP: The deacetylase HDAC6 regulates aggresome formation and cell viability in response to misfolded protein stress. Cell 115: 727-738, 2003.

8. Kwon S, Zhang Y and Matthias P: The deacetylase HDAC6 is a novel critical component of stress granules involved in the stress response. Genes Dev 21: 3381-3394, 2007.

9. Zhang Y, Kwon S, Yamaguchi T, Cubizolles F, Rousseaux S, Kneissel M, Cao C, Li N, Cheng HL, Chua K, et al: Mice lacking histone deacetylase 6 have hyperacetylated tubulin but are viable and develop normally. Mol Cell Biol 28: 1688-1701, 2008.

10. Bergman JA, Woan K, Perez-Villarroel P, Villagra A, Sotomayor EM and Kozikowski AP: Selective histone deacetylase 6 inhibitors bearing substituted urea linkers inhibit melanoma cell growth. J Med Chem 55: 9891-9899, 2012.
11. Butler LM, Agus DB, Scher HI, Higgins B, Rose A, Cordon-Cardo C, Thaler HT, Rifkind RA, Marks PA and Richon VM: Suberoylanilide hydroxamic acid, an inhibitor of histone deacetylase, suppresses the growth of prostate cancer cells in vitro and in vivo. Cancer Res 60: 5165-5170, 2000.

12. Inks ES, Josey BJ, Jesinkey SR and Chou CJ: A novel class of small molecule inhibitors of HDAC6. ACS Chem Biol 7: 331-339, 2012.

13. Santo L, Hideshima T, Kung AL, Tseng JC, Tamang D, Yang M, Jarpe M, van Duzer JH, Mazitschek R, Ogier WC, et al: Preclinical activity, pharmacodynamic, and pharmacokinetic properties of a selective HDAC6 inhibitor, ACY-1215, in combination with bortezomib in multiple myeloma. Blood 119: 2579-2589, 2012.

14. Smil DV, Manku S, Chantigny YA, Leit S, Wahhab A, Yan TP, Fournel M, Maroun C, Li Z, Lemieux AM, et al: Novel HDAC6 isoform selective chiral small molecule histone deacetylase inhibitors. Bioorg Med Chem Lett 19: 688-692, 2009.

15. Estiu G, Greenberg E, Harrison CB, Kwiatkowski NP, Mazitschek R, Bradner JE and Wiest O: Structural origin of selectivity in class II-selective histone deacetylase inhibitors. J Med Chem 51: 2898-2906, 2008.

16. Haggarty SJ, Koeller KM, Wong JC, Grozinger CM and Schreiber SL: Domain-selective small-molecule inhibitor of histone deacetylase 6 (HDAC6)-mediated tubulin deacetylation. Proc Natl Acad Sci USA 100: 4389-4394, 2003.

17. Dallavalle S, Pisano $C$ and Zunino F: Development and therapeutic impact of HDAC6-selective inhibitors. Biochem Pharmacol 84: 756-765, 2012.

18. Ashjian E and Redic K: Multiple myeloma: Updates for pharmacists in the treatment of relapsed and refractory disease. J Oncol Pharm Pract 22: 289-302, 2016.

19. Vogl DT, Raje N, Jagannath S, Richardson P, Hari P, Orlowski R, Supko JG, Tamang D, Yang M, Jones SS, et al: Ricolinostat, the first selective histone deacetylase 6 inhibitor, in combination with bortezomib and dexamethasone for relapsed or refractory multiple myeloma. Clin Cancer Res 23: 3307-3315, 2017.

20. Yee AJ, Bensinger WI, Supko JG, Voorhees PM, Berdeja JG, Richardson PG, Libby EN, Wallace EE, Birrer NE, Burke JN, et al: Ricolinostat plus lenalidomide, and dexamethasone in relapsed or refractory multiple myeloma: A multicentre phase $1 \mathrm{~b}$ trial. Lancet Oncol 17: 1569-1578, 2016.

21. Dasmahapatra G, Patel H, Friedberg J, Quayle SN, Jones SS and Grant S: In vitro and in vivo interactions between the HDAC6 inhibitor ricolinostat (ACY1215) and the irreversible proteasome inhibitor carfilzomib in non-Hodgkin lymphoma cells. Mol Cancer Ther 13: 2886-2897, 2014.

22. Chou TC: Drug combination studies and their synergy quantification using the Chou-Talalay method. Cancer Res 70: 440-446, 2010.

23. Witter DJ, Harrington P, Wilson KJ, Chenard M, Fleming JC, Haines B, Kral AM, Secrist JP and Miller TA: Optimization of biaryl Selective HDAC1\&2 Inhibitors (SHI-1:2). Bioorg Med Chem Lett 18: 726-731, 2008

24. Hideshima T, Cottini F, Ohguchi H, Jakubikova J, Gorgun G, Mimura N, Tai YT, Munshi NC, Richardson PG and Anderson KC: Rational combination treatment with histone deacetylase inhibitors and immunomodulatory drugs in multiple myeloma. Blood Cancer J 5: e312, 2015

25. Mishima Y, Santo L, Eda H, Cirstea D, Nemani N, Yee AJ, O'Donnell E, Selig MK, Quayle SN, Arastu-Kapur S, et al: Ricolinostat (ACY-1215) induced inhibition of aggresome formation accelerates carfilzomib-induced multiple myeloma cell death. Br J Haematol 169: 423-434, 2015.

26. Quayle SN and Jones SS: ACY-1215, a first-in-class selective inhibitor of HDAC6, demonstrates significant synergy with immunomodulatory drugs (IMiDs) in preclinical models of multiple myeloma (MM). Blood 122: 1952, 2013.

27. Ryu HW, Shin DH, Lee DH, Won HR and Kwon SH: A potent hydroxamic acid-based, small-molecule inhibitor A452 preferentially inhibits HDAC6 activity and induces cytotoxicity toward cancer cells irrespective of p53 status. Carcinogenesis 39: 72-83, 2018.

28. Falkenberg KJ and Johnstone RW: Histone deacetylases and their inhibitors in cancer, neurological diseases and immune disorders. Nat Rev Drug Discov 13: 673-691, 2014.

29. Marks PA and Xu WS: Histone deacetylase inhibitors: Potential in cancer therapy. J Cell Biochem 107: 600-608, 2009.

30. Bruserud O, Stapnes C, Ersvaer E, Gjertsen BT and RyningenA: Histone deacetylase inhibitors in cancer treatment: A review of the clinical toxicity and the modulation of gene expression in cancer cell. Curr Pharm Biotechnol 8: 388-400, 2007. 
31. Kaliszczak M, Trousil S, Åberg O, Perumal M, Nguyen QD and Aboagye EO: A novel small molecule hydroxamate preferentially inhibits HDAC6 activity and tumour growth. Br J Cancer 108: 342-350, 2013.

32. Alzoubi S, Brody L, Rahman S, Mahul-Mellier AL, Mercado N, Ito K, El-Bahrawy M, Silver A, Boobis A, Bell JD, et al: Synergy between histone deacetylase inhibitors and DNA-damaging agents is mediated by histone deacetylase 2 in colorectal cancer. Oncotarget 7: 44505-44521, 2016.

33. Flis S, Gnyszka A and Spławiński J: HDAC inhibitors, MS275 and SBHA, enhances cytotoxicity induced by oxaliplatin in the colorectal cancer cell lines. Biochem Biophys Res Commun 387: 336-341, 2009
34. Wang Z, Hu P, Tang F, Lian H, Chen X, Zhang Y, He X, Liu W and Xie C: HDAC6 promotes cell proliferation and confers resistance to temozolomide in glioblastoma. Cancer Lett 379: 134-142, 2016.

35. Huang P, Almeciga-Pinto I, Jarpe M, van Duzer JH, Mazitschek R, Yang M, Jones SS and Quayle SN: Selective HDAC inhibition by ACY-241 enhances the activity of paclitaxel in solid tumor models. Oncotarget 8: 2694-2707, 2017. 